\title{
MYTHS AND REALITIES OF CHARGING DRI/HBI IN ELECTRIC ARC FURNACES*
}

\author{
Sara Hornby ${ }^{1}$ \\ Jorge Madias ${ }^{2}$ \\ Francisco Torre ${ }^{3}$
}

\begin{abstract}
After almost half a century of experience in using DRI/HBI in electric arc furnaces (EAFs), and taking into account the decrease of natural gas cost in the USA, it is interesting to revisit some trends and controversial issues around this alternative iron source. This paper reviews aspects like the evolution of iron ore quality and its influence on EAF operation; DRI stockpiling and transport, regarding the risk for selfcombustion; optimum charge design; cold $\mathrm{DRI} / \mathrm{HBI}$ charging (fifth hole, bucket, transporter); hot charging (ways and results); carbon content, metallization and silica in $\mathrm{DRI} / \mathrm{HBI}$, and its influence on EAF operation and performance; oxygen / carbon balance; chemical energy and $\mathrm{DRI} / \mathrm{HBI}$ charge.
\end{abstract}

Keywords: DRI; HBI; EAF; Energy consumption. 


\section{INTRODUCTION}

\subsection{Myth - DRI use Significantly Increases Steel Costs x Reality - Not if Mills Optimize Operations}

The production of $\mathrm{DRI} / \mathrm{HBI}$ has grown almost exponentially since its inception in the early seventies (Figure 1) [1]. In Mexico, Trinidad and Argentina steel mills use DRI supplied by captive plants. In Venezuela DRI is produced for captive steel production and $\mathrm{HBI}$ is produced for export. Recently, Venezuelan production has been curtailed significantly leaving world merchant supply lacking. This dearth (and dependence) has renewed interest in $\mathrm{DRI} / \mathrm{HBI}$ production in the USA where current availability and price evolution of natural gas (NG) has made low cost production of these alternative iron sources (AIS') possible.

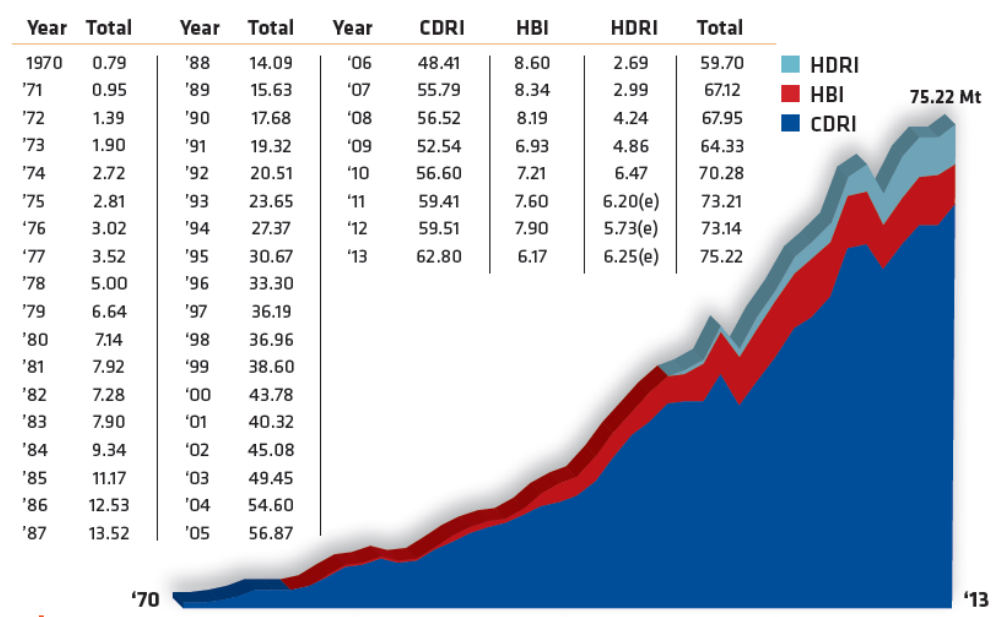

Figure 1. World Production of DRI and HBI, 1970-2014 [1].

In this paper, aspects of DRI and HBI production and use, such as iron ore quality, stockpiling and transportation, optimum charge design and charging method, temperature and chemistry of the $\mathrm{DRI}$ and $\mathrm{HBI}$, and its influence on EAF operation, energy balance and performance are reviewed. Note: Unless otherwise indicated, $\mathrm{DRI}$ is used to refer to both $\mathrm{DRI}$ and $\mathrm{HBI}$.

\section{EVOLUTION OF IRON ORE QUALITY AND ITS INFLUENCE ON EAF OPERATION}

\subsection{Myth: Iron Ore Quality is Constant; Reality - It is Diminishing}

Most gas-based DRI is produced using pellets as DRI quality lump ore is rarely available. The production of iron ore for pellets usually includes concentration steps to improve quality. Although this has an influence on gangue and phosphorus content, it is not enough to compensate for the decrease in DRI pellet feed quality. The lower quality is related to the over-exploitation of the best iron ore resources during the first 8 years of this century [2].

Besides gangue and phosphorus, sulfur released during pellet reduction is important for those modules that use process gas in the reformer. Furthermore, pelletizing operations may add silica and alumina gangue from the binder and sulfur from the fuel used for induration. Many DRI pellet producers use organic binders instead of bentonite to lower gangue content [3], imbue superior metallurgical and chemical 
qualities, hence, improve EAF operations and lower overall steel productions costs. With a higher initial cost than bentonite, the organic binder Peridur can save $\$ 1.81 /$ ton liquid steel $\left(\mathrm{t}_{\mathrm{ls}}\right)$ and $\$ 1.00 / \mathrm{t}_{\text {ls }} \quad\left(\$ 1.65 / \mathrm{Tonne}_{\text {Is }}\left(\mathrm{Te}_{\mathrm{ls}}\right)\right.$ and $\left.\$ 0.91 / \mathrm{Te}_{\mathrm{ls}}\right)$ respectively for $100 \%$ and $50 \%$ replacement of bentonite when considering the cost of fluxes, power, yield loss and slag disposal for 94\% metallization (Met.) DRI [4]. Miners are attempting to counteract the lower iron ore quality by changing concentration schemes $[5,6]$ and using new approaches to better understand relationships between mineralogy and behavior during pelletizing and reduction [7].

\section{RISK OF SELF-COMBUSTION DURING DRI STOCKPILING AND TRANSPORT}

\subsection{Myth - DRI Cannot be Shipped Distances x Reality - More DRI than HBI is Shipped Today}

Despite the known self-combustion (auto-ignition) risks involved in stockpiling and transport of DRI, more DRI than HBI has been shipped annually since 2006: in 2013, 8.56 MTe (9.42Mt) DRI vs. 5.65 MTe (6.22Mt) HBI - Venezuelan HBI shipments to the USA alone decreased from $1.8 \mathrm{MTe}(1.98 \mathrm{Mt})$ to $0.5 \mathrm{MTe}(0.55 \mathrm{Mt})$. Generally, DRI is shipped shorter distances than HBI though Acindar and Nucor import DRI from Trinidad. Increased DRI shipments and the need for some plants to stockpile DRI to compensate for winter downtime due to natural gas scarcity, has caused the subject of DRI auto-ignition to be revisited recently [8,9]. Figure 2 shows the merchant DRI and $\mathrm{HBI}$ production sites and worldwide trade routes respectively $[1,10]$.
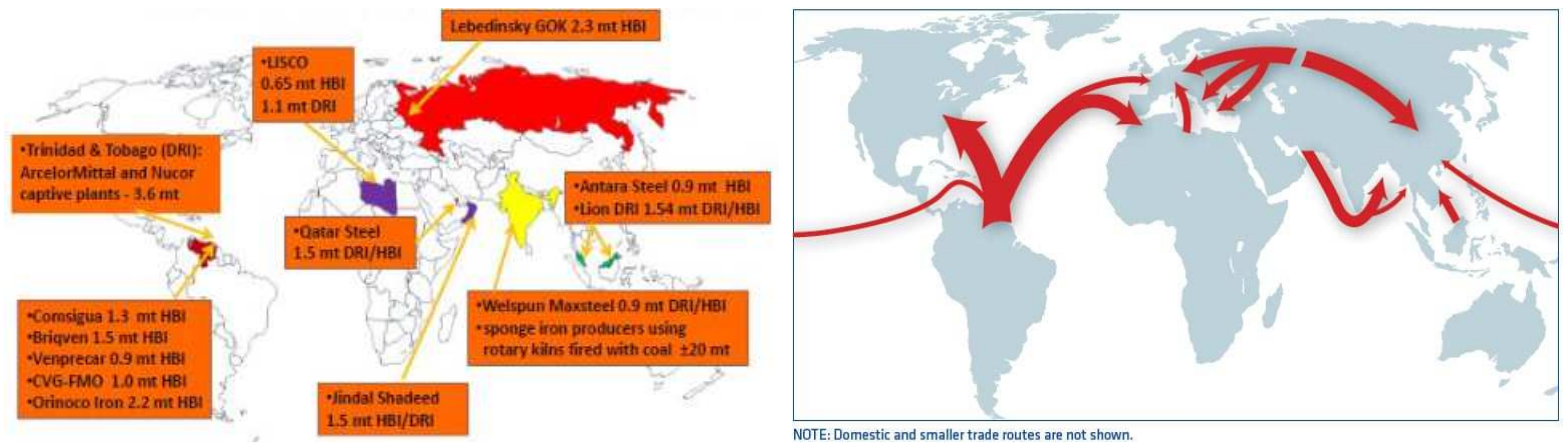

Figure 2. a) Merchant DRI \& HBI Production Sites [10]; b) Major Trade Routes for DRI (HBI \& CDRI) [1].

Figure 2a shows the worldwide $\mathrm{DRI}$ and $\mathrm{HBI}$ merchant production reported by the International Iron Metallics Association (IIMA) conference in 2012 [10]. From the total Venezuelan production (6.9MTe; 7.59Mt), this map represents 2008 production [1]. 2013 Venezuelan merchant dropped to $2.8 \mathrm{MTe}$. Figure $2 \mathrm{~b}$ shows the major trade routes for this merchant $\mathrm{DRI} / \mathrm{HBI}$ production reported in the worldwide DRI Statistics for year-end 2013 [1]. The width of the lines indicate the amount of DRI/HBI traveling the routes and was drawn from the Iron and Steel Statistics Bureau (ISSB), the Iron Metallics Association (IIMA) and reports from individual operating plants. (Note: 2MTe exported from these plants are not accounted for in the import data [1]). Only Russia and Venezuela typically supply further afield than the regional markets. A well-known example of DRI transportation is from the Nu-Iron plant in Trinidad to USA ports - Charleston, South Carolina, Mobile, Alabama and New Orleans, Louisiana. After discharge at the docks, the product is transported via barges to the receiving mills. Specific procedures are followed for passivation of the DRI in the plant, loading into the ship, inerting of the cargo, and barge transportation etc. [11]. 


\section{CHARGING}

\subsection{Myth - DRI use Increases Liquid Steel Cost x Reality - Not if Mills use VIU to Define Charge Mixes}

\subsubsection{Optimum Charge Design [12,13]}

Charge mix optimization strategy is very important considering the charge constitutes $73 \%$ to $89 \%$ of the total cost of liquid steel in an EAF [12]. Historically, mills believed use of $\mathrm{DRI} / \mathrm{HBI}$ carried an $\$ 8$ to $\$ 30$ premium due to the penalties (higher $\mathrm{kWh} / \mathrm{ton}_{\text {ls }}$ $\left(\mathrm{kWh} / \mathrm{Te}_{\mathrm{Is}}\right)$, Tap to Tap times (TTT), fluxes, slag $\mathrm{FeO}$ content $\left(\mathrm{FeO}_{\text {slag }}\right)$, refractories and electrode wear, yield losses). These increased operating costs predicated DRI EAF use for high quality, low residuals steels' production only. This is true if the EAF operators use $\mathrm{DRI} / \mathrm{HBI}$ without identifying and understanding the inherent and unique properties and modifying practices accordingly. Educated EAF operators have established standard operating practices (SOPs) that not only negate the preconceived disadvantages, but actually improve operations and operating costs. Table 1 [13] shows use of 50\% DRI (composition: $93 \% \mathrm{Fe}$ total, $93 \%$ Met., $1.8 \% \mathrm{C}$, $\left.1.5 \%(\mathrm{CaO}+\mathrm{MgO}), 1.9 \%\left(\mathrm{SiO}_{2}+\mathrm{Al}_{2} \mathrm{O}_{3}\right), 0.003 \% \mathrm{~S}\right)$ can reduce $\mathrm{kWh} / \mathrm{t}_{\text {charged }}$ and TTT below that for $100 \%$ scrap. Note: these days $93 \%$ Met. is considered low and the basicity is now more normally 0.4 to 0.5 vs. the 0.79 cited in the composition given, especially when operating $60 \%$ to $65 \%$ DRI.

Table 1. \%DRI Impact on Operating Parameters

\begin{tabular}{|c|c|c|}
\hline \%DRI & kWh/ton & $\begin{array}{c}\text { TTT } \\
\text { (mins) }\end{array}$ \\
\hline $\begin{array}{c}\text { All } \\
\text { Scrap }\end{array}$ & 421 & 61 \\
\hline 25 & 375 & 52 \\
\hline 30 & 377 & 53 \\
\hline 35 & 380 & 54 \\
\hline 40 & 393 & 55 \\
\hline 45 & 399 & 57 \\
\hline 50 & 408 & 59 \\
\hline
\end{tabular}

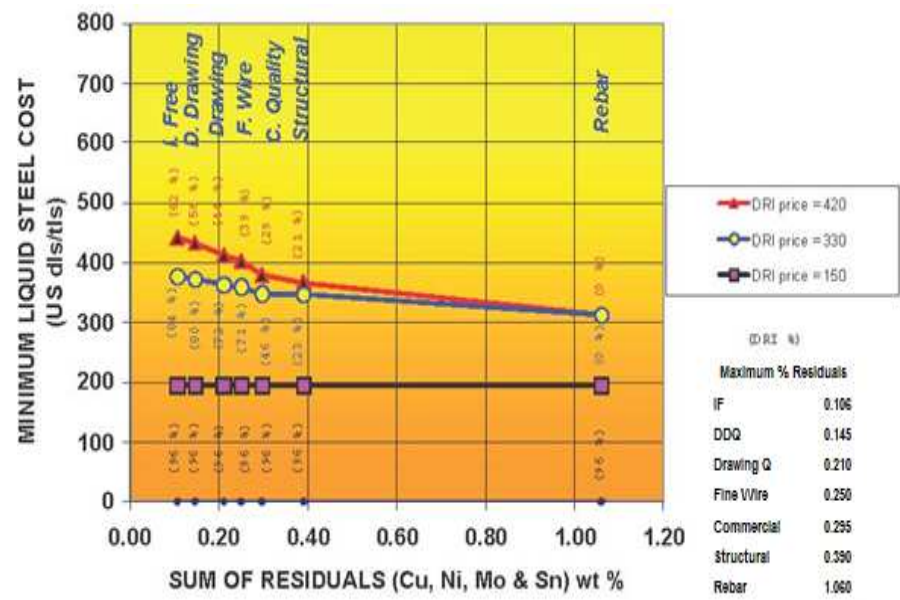

Figure 3. Summary of DRI VIU Results for 7 Steel Grades [12]

To achieve lower operating costs, steel mills must truly understand and quantify their current operating efficiencies, optimize their practices by charge mix and accurately define yield. Cost of variables associated with DRI use need to be quantified continuous charging, safety and ease of handling (shipping, transfer, sorting, storage, charging...), nitrogen removal capacity, carbon efficiency (contained, in-situ, versus injection or charging - see below), and practice changes needed to accommodate DRI use. Only then will the true value of DRI be revealed. Enter the most important concept for defining optimized charges - the Value in Use (VIU) of metallics.

The VIU balances the raw material's cost, quality, chemistry, yield, charging method (continuous or batch) and temperature with the operational impact of individual metallics on the cost of converting them to liquid steel of the correct composition and quality. Conversion costs include site-specific operational and product chemistry constraints, such as the cost of consumables (power, electrodes, oxygen $\left(\mathrm{O}_{2}\right)$, 
carbon, natural gas (NG), fluxes, alloys, refractories, stirring plugs, roof life, ancillary equipment), generation and disposal penalty of wastes (slag, dust and yield loss), recovery of metallics, and local metallics supply (material, delivery, storage, inventory, carrying costs etc.), and environmental impact, all of which impact the bottom line. These costs and the costs of constraints will determine the true cost of melting a ton $\mathrm{Is}_{\mathrm{s}}\left(\mathrm{Te}_{\mathrm{ls}}\right)$ [12]. This VIU is site specific and needs to be defined and assigned for each charge material considering the Region (local, national, international) and current economy.

\subsubsection{Charging Methodology}

As the use of DRI has increased worldwide, charging methods have changed. High $\% D R I$ charges abound in captive DRI plants (captive due to poor quality or low availability of scrap - Argentina, MENA) and direct supply to the EAF via a continuous charging system to a $5^{\text {th }}$ hole is available. Invariably there are storage bins or large warehouses to accept DRI supply when the EAF shop is down for maintenance or delays or when stock piling is required for DRI plant shut downs.

\subsubsection{Bucket Charging}

Bucket Charging is used by steel mills generally using less than $25 \%$ to $30 \% \mathrm{DRI} / \mathrm{HBI}$ though it is preferable to continuously charge $\mathrm{DRI}$. DRI/HBI in the bucket aids charge densification as well as lowering residuals in liquid steel. Bucket charging circumvents the cost of a continuous charging system. $\mathrm{HBI}$ is usually charged on top of heavy scrap or bundles to maximize densification of the charge and the rest of the bucket is loaded according to the site-specific practice(s) $[13,16]$. $\mathrm{HBI}$ is usually divided between buckets in multiple bucket charges with more in the last bucket to improve the melt refining where the lower \%C and increased $\mathrm{O}_{2}$ content can compensate for lack of $\mathrm{O}_{2}$ input capacity and minimize blow down at the end of the heat. If a single bucket charge practice is used, $\mathrm{HBI}$ is input in multiple layers. $\mathrm{HBI}$ tonnage is usually limited to reduce iceberg formation. DRI is charged higher up (third and penultimate layers) in the bucket to prevent DRI falling through the bottom of the bucket.

\subsubsection{Fifth Hole (Roof)}

Fifth Hole (Roof) charging is preferred for DRI and is definitely more efficient when using more than $30 \%$ DRI. Continuous charging facilitates coordination of the feed rate with the power input and flux feeding to ensure slag control (foaming height, viscosity etc.) and prevent ferrobergs which will occur when cold DRI is charged too fast. Continuously charging hot $\left(600^{\circ} \mathrm{C}\right) \mathrm{DRI}$ can reduce energy required by as much as $16 \%$ to $20 \%$.

\subsubsection{Side Charging (Consteel [17] or equivalent)}

Side Charging is more appropriate for $\mathrm{HBI}$ charging and can be combined with continuously feeding DRI through the roof. This set-up has significant benefits over a conventional EAF as the constant flat bath operating condition allows immediate feeding of DRI at a slower rate (less chance of ferrobergs) over a longer period; continuous flux additions control the slag composition more readily; the $\mathrm{HBI}$ is preheated on the belt as it travels to the EAF. 


\subsubsection{Continuous versus Batch Charging [12]}

Continuous feeding significantly reduces the EAF energy requirement because it affords closed-door operation. This negates heat and time losses from roof swing(s) and charging, not to mention potential nitrogen pick-up arising from air ingress occurring when the roof is open. Table 2, comparing continuous versus batch (bucket) charging, shows continuously charged 33\% DRI has the best results, saving $46 \mathrm{kWh} / \mathrm{t}$ charged $\left(\mathrm{t}_{\mathrm{c}} ; 50.6 \mathrm{kWh} / \mathrm{Te}_{\mathrm{c}}\right)$ and 4 minutes TTT. Even continuously feeding $43 \% \mathrm{DRI}$ saves $34 \mathrm{kWh} / \mathrm{t}_{\mathrm{c}}\left(37.4 \mathrm{kWh} / \mathrm{Te}_{\mathrm{c}}\right)$ compared to the two (2) bucket charge even though TTT is identical.

Table 2. Continuous vs. Batch Charging of DRI $[13,14]$

\begin{tabular}{|l|c|c|}
\hline & $\mathbf{k W h} / \mathbf{t}$ & $\begin{array}{c}\text { TTT } \\
\text { (mins) }\end{array}$ \\
\hline $\begin{array}{l}33 \% \mathrm{DRI}-2 \text { bucket } \\
\text { charge }\end{array}$ & 426 & 58 \\
\hline $\begin{array}{l}33 \% \mathrm{DR}-\text { continuous } \\
\text { charge }\end{array}$ & 380 & 54 \\
\hline $\begin{array}{l}43 \%-=33 \% \text { cont., 10\% } \\
\text { charge }\end{array}$ & 390 & 55 \\
\hline $43 \% \mathrm{DRI}-$ continuous & 392 & 58 \\
\hline
\end{tabular}

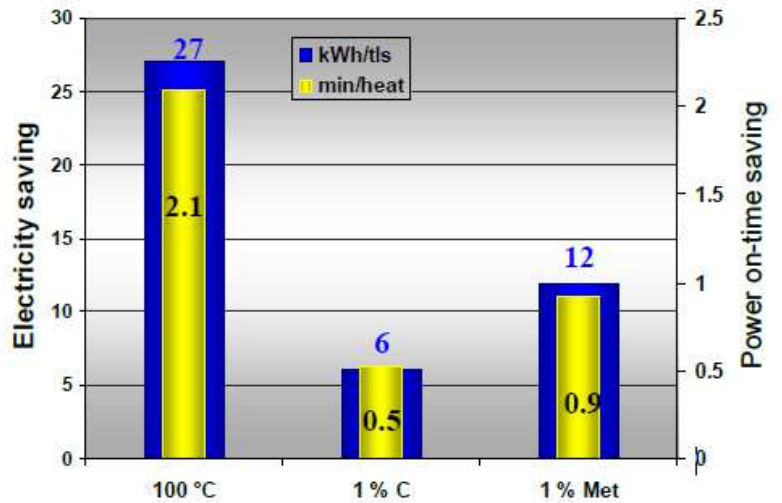

Figure 4. Savings Available from DRI Variations [12].

\subsubsection{Cold versus Hot Charging}

As previously mentioned hot charging DRI reduces the power requirement by $20 \mathrm{kWh}$ to $30 \mathrm{kWh} / 100^{\circ} \mathrm{C}$. Figure 4 shows $27 \mathrm{kWh} / \mathrm{Te}_{\mathrm{Is}}\left(24.6 \mathrm{kWh} / \mathrm{t}_{\mathrm{ls}}\right)$ [12]. Tenova has reported also [17] only $375 \mathrm{kWh} / \mathrm{Te}\left(340.9 \mathrm{kWh} / \mathrm{t}_{\mathrm{ls}}\right)$ is required to melt $100 \% \mathrm{DRI}$ with $4 \% \mathrm{C}$ charged at $600^{\circ} \mathrm{C}$ using $42 \mathrm{Nm}^{3} \mathrm{O}_{2} / \mathrm{Te}_{\text {Is }}\left(1377 \mathrm{hcf} / \mathrm{t}_{\mathrm{ls}}\right)$. Preheating $\mathrm{DRI}$ to $600^{\circ} \mathrm{C}$ at Essar [13,14], whilst necessitating a slower DRI feed rate to prevent EAF carbon (C) boils, resulted in power, electrode and TTT savings (124 to $145 \mathrm{kWh} / \mathrm{Te}$ (112.7 to $131.9 \mathrm{kWh} / \mathrm{t}), 0.3 \mathrm{~kg}$ electrodes $/ \mathrm{Te}_{\mathrm{ss}}\left(0.6 \mathrm{lb}\right.$ electrodes $\left./ \mathrm{t}_{\mathrm{ls}}\right)$ and $0.06 \mathrm{~min} . / \mathrm{Te}_{\text {HDRl }}(0.054$ min./ $\left.\mathrm{t}_{\mathrm{HDRI}}\right)$. A reduction in $\mathrm{DRI} \mathrm{FeO}$ content versus their normal $\mathrm{HBI}$ production was seen. Combining the AM Mexico cold DRI (CDRI) data (Column 1 and 2, Table 3) with Essar hot DRI (HDRI) results, savings of $191 \mathrm{kWh}$ and $\$ 9.27 /$ Tonne (173.7kWh and $\$ 8.42 / \mathrm{t}$ ) are expected when charging $94.4 \%$ of $3.1 \% \mathrm{C} \mathrm{DRI}$ at $700^{\circ} \mathrm{C}$ (column 3 , Table 3).

Table 3. Economic* impact of 3.1\%C HDRI in an EAF [15]

\begin{tabular}{|c|c|c|c|}
\hline \% Carbon in DRI & $2.08 \%$ & $3.10 \%$ & $3.10 \%$ \\
\hline Charge \%DRI/Scrap (Te $\left.\mathrm{DR}_{\mathrm{DR}} / \mathrm{Te}_{\mathrm{scrap}}\right)$ & \multicolumn{3}{|c|}{$94.4 / 5.6 \quad(252 / 15)$} \\
\hline DRI Temperature $\left({ }^{\circ} \mathrm{C}\right)$ & & 25 & 700 \\
\hline Scrap Temperature $\left({ }^{\circ} \mathrm{C}\right)$ & \multicolumn{3}{|c|}{25} \\
\hline \% Metallization & \multicolumn{3}{|c|}{95} \\
\hline$\%$ Yield & \multicolumn{3}{|c|}{90} \\
\hline Power on Time (minutes) & 66 & 57 & 38.9 \\
\hline Tap to Tap Time (minutes) & 80 & 71 & 53.9 \\
\hline Total Energy $\left(\mathrm{kWh} / \mathrm{Te}_{\mathrm{Is}}\right)$ & 585.9 & $527(-58.9)$ & $419.1(-191.11)$ \\
\hline Productivity (Te/hour) & 163 & $177(+14)$ & $222(+59)$ \\
\hline $\begin{array}{l}\text { Savings @ \$0.035/kWh } \\
@ \$ 0.050 / \mathrm{kWh}\end{array}$ & & $\begin{array}{l}4.64 \\
5.53\end{array}$ & $\begin{array}{c}9.27 \\
12.14\end{array}$ \\
\hline
\end{tabular}

\footnotetext{
${ }^{*}$ Economics assigned by the authors
} 


\section{CARBON CONTENT, METALLIZATION AND SILICA IN DRI/HBI, AND THEIR INFLUENCE ON EAF OPERATION AND PERFORMANCE}

\subsection{Myth - DRI is Detrimental to EAF Operations x Reality - Not if SOPs are Optimized}

\subsubsection{Carbon}

High $\mathrm{FeO}_{\text {slag }}$ increases refractory erosion. Neutralization requires the DRI contain $0.215 \% \mathrm{C}$ for every $1 \% \mathrm{Fe}$ as FeO. So, $93 \%$ Met. DRI with $93 \%$ total iron, theoretically requires $1.4 \% \mathrm{C}$ for "neutralization". Any excess carbon is available for combustion with oxygen and will reduce electrical energy requirements $(4.13 \mathrm{kWh}$ is available from combustion of $1 \mathrm{lb} \mathrm{C}$ at $100 \%$ efficiency $(9.09 \mathrm{kWh} / \mathrm{kg}))$. The excess carbon promotes also a faster, earlier, foamy slag reaction as $\mathrm{FeO}_{\mathrm{DRI}}$ melts and $\mathrm{CO}$ and/or $\mathrm{CO}_{2}$ are evolved.

In the early 1990's the majority of steelmakers requested $1.6 \% \mathrm{C}$ to $1.8 \% \mathrm{C} \mathrm{DRI}$ due to lack of $\mathrm{O}_{2}$ tools and/or $\mathrm{O}_{2}$ supply to economically decarburize (deC) the melt. With the advent of more efficient $\mathrm{O}_{2}$ practices, larger off-gas systems (OGS') and quantification of economics and efficiency of contained (in-situ) carbon, higher \%C $\mathrm{DRI}$ is used today. In 1999, the average \%C in Midrex DRI/HBI was $1.77 \% \mathrm{C}$ $(0.49 \% \mathrm{C}$ to $2.23 \% \mathrm{C})$ and metallization ranged from $91.29 \%$ to $96.31 \%$. AM Mexico increased their \%C to between $2.5 \% \mathrm{C}$ and $3.1 \% \mathrm{C}$ in 1999.

Today, the optimal DRI carbon content is controversial. Some continue to fear the cost impact of iron loss due to carbon replacement thereof versus the cost and energy benefit derived from the in-situ carbon efficiency. Heat transfer to the bath from charged/injected carbon is $25 \%$ to $75 \%$ efficient, while AM Mexico reports $95 \%$ efficiency from DRI in-situ carbon [13,15]. AM Mexico realized modified SOPs were needed when they increased DRI carbon from $2.7 \%$ to $3.1 \%$ [13]. SOP changes included negation of charge/injected carbon, earlier $\mathrm{O}_{2}$ use, faster $\mathrm{DRI}$ charge rate due to the improved, earlier foamy slag, better heat transfer and bath reactions achieved from in-situ carbon. Table 3 shows the $\$ 4.64 / \mathrm{Te}_{\mathrm{Is}}\left(\$ 4.21 / \mathrm{t}_{\mathrm{ls}}\right)$ is saved when $94.4 \% \mathrm{DRI}$ is charged and power cost is $\$ 0.035 / \mathrm{kWh}$. This carbon efficiency, coupled with the low residual properties, provide benefits such as: economic residual control; lower $[\mathrm{N}]_{\text {steel }}$ and $[\mathrm{H}]_{\text {steel }}$ because of improved, earlier, foamy slag and $\mathrm{CO}$ purging; reduced energy use, TTT, refractory and electrode wear; increased yield and productivity; lower cost liquid steel (Table 3, Figure 4) [12,15,17].

\subsubsection{Metallization}

Table 4 shows the benefits derived from a 1\% increase in metallization (defined as a percentage of the ratio of metallic to total iron) at Acindar [13,19], Ternium Guerrero [4] and industry in general. Figure $5 \mathrm{a}$ and $5 \mathrm{~b}$ graphically represent the impact at Acindar. Savings of 10 to $25 \mathrm{kWh}, 0.425 \mathrm{~kg}$ refractories and $0.0375 \mathrm{~kg}$ electrodes $/ \mathrm{Te}_{\mathrm{ls}}\left(9.1\right.$ to $22.7 \mathrm{kWh}, 0.85 \mathrm{lbs}$ refractories, $0.075 \mathrm{lbs}$ electrodes $\left./ \mathrm{t}_{\mathrm{ls}}\right)$ with between $0.3 \%$ and $2 \%$ increase in yield were realized. Increasing metallization from $91 \%$ to $95 \%$ reduced power $40 \mathrm{kWh} / \mathrm{Te}(36.4 \mathrm{kWh} / \mathrm{t})$ and increased yield $1.5 \% / 1 \%$ increase in metallization. 
Table 4. Benefits of a $1 \%$ Increase in Metallization of DRI/HBI

\begin{tabular}{|c|c|c|c|}
\hline Benefits Category & General & Acindar [13] & $\begin{array}{c}\text { Ternium } \\
\text { Guerrero [4] }\end{array}$ \\
\hline KWh/T liquid steel & 10 to 25 & 25 & 12 \\
\hline Refractory savings/Tonne Is $_{\text {s }}$ & $0.425 \mathrm{~kg}$ & $\$ 0.70$ & \\
\hline Electrode savings/Tonne is & $0.0375 \mathrm{~kg}$ & $0.15 \mathrm{~kg}$ & \\
\hline Yield Increase & $0.3 \%$ to $2 \%$ & $1 \%$ & $-4 \mathrm{~kg} / \mathrm{t}$ \\
\hline Coke savings/Tonne ${ }_{\text {liquid steel }}$ & 0 to $4 \mathrm{~kg}$ & $5.8 \mathrm{~kg}$ & \\
\hline Productivity Increase & Up to $5 \%$ & Up to $5 \%$ & \\
\hline Cost Reduction (VIU)/Tonne $\mathrm{Is}_{\mathrm{s}}$ & $\$ 0.68$ to $\$ 2.96$ & $\$ 6.00$ to $\$ 8.09$ & $\$ 5.00$ \\
\hline Increase in Metallization & $92 \%$ to $93 \%$ & $93.5 \%$ to $94.5 \%$ & \\
\hline
\end{tabular}
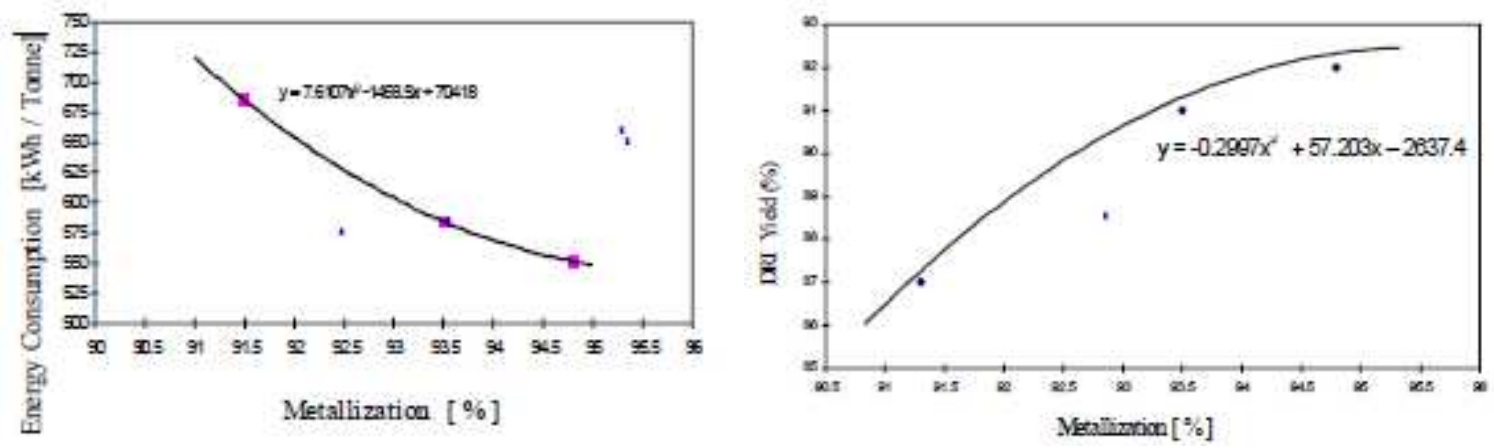

Figure 5. a) kWh/Te vs. Metallization [13,19]; b) DRI Yield vs. Metallization at Acindar [13].

\subsubsection{Gangue}

The high oxide content in DRI has detrimental process effects. For example a $10 \%$ DRI charge requires an additional $15 \mathrm{kWh} / \mathrm{Te}_{\mathrm{ls}}, 0.19 \mathrm{~kg} / \mathrm{Te}_{\mathrm{ls}}\left(13.63 \mathrm{kWh} / \mathrm{t}_{\mathrm{s}}, 0.38 \mathrm{lb} / \mathrm{t}_{\mathrm{ls}}\right)$, 2.5 mins. TTT, slag former use (hence greater slag volume and disposal cost) and presents a loss of $0.4 \%$ yield and productivity. For every $1 \%$ decrease in metallization the power requirement increases by between $8 \mathrm{kWh} / \mathrm{Te}$ and $16 \mathrm{kWh} / \mathrm{Te}(7.3 \mathrm{kWh} / \mathrm{t}$ to $14.6 \mathrm{kWh} / \mathrm{t})$. Contrarily, $10 \% \mathrm{PI}$ (4\% carbon, low oxide) lowers the power requirement by $27.1 \mathrm{kWh} / \mathrm{Te}_{\mathrm{ls}}\left(24.6 \mathrm{kWh} / \mathrm{t}_{\mathrm{ls}}\right)$.

The scrap "gangue" content can be as high as $10 \%$, when considering low quality obsolete scrap, which contains dirt and other non-metallics. Table 5 shows a comparative analysis of DRI and average scrap at AM Mexico [13]. Increasing the acid gangue content by $1 \%$ will increase the basic fluxes $\left(\mathrm{MgO}\right.$ and $\left.\mathrm{SiO}_{2}\right)$ to satisfy the quaternary EAF slag "V" ratio $\left(\mathrm{V}_{4}\right)$. CaO must increase $2 \%$ for each $1 \% \mathrm{SiO}_{2}$, but the relationship is exponential (not linear) when $\mathrm{SiO}_{2}$ is higher than $2 \%$. This will increase power requirements by $20 \mathrm{kWh} / \mathrm{Te}(18.2 \mathrm{kWh} / \mathrm{t})$, as well as increase the slag volume and disposal costs. Table 7 shows additional cost penalties associated with various gangue components in Asian mills as defined by BHP Steel $[12,13,15]$. 
Table 5. Scrap and DRI Compositions at AM Mexico

\begin{tabular}{|l|c|c|c|c|}
\hline $\begin{array}{l}\text { AM } \\
\text { Mexico }\end{array}$ & $\begin{array}{c}\text { Total } \\
\text { Fe }\end{array}$ & $\%$ FeO & $\%$ C & $\begin{array}{c}\text { \%Gang } \\
\text { ue }\end{array}$ \\
\hline DRI & 90.80 & 6.77 & $\begin{array}{c}2.0 \\
8\end{array}$ & 4.47 \\
\hline $\begin{array}{l}\text { Ave. } \\
\text { Scrap }\end{array}$ & 93.85 & 1.80 & $\begin{array}{c}0.4 \\
7\end{array}$ & 4.25 \\
\hline
\end{tabular}

Table 6. Impact of Excess Combustible Carbon at AM Montreal East

\begin{tabular}{|c|c|c|c|}
\hline $\begin{array}{c}\text { DRI } \\
\% \mathbf{C}\end{array}$ & $\begin{array}{c}\text { \%Fe } \\
\mathbf{O}\end{array}$ & $\begin{array}{c}\mathbf{9 2 . 5 \%} \\
\text { Met }\end{array}$ & $\begin{array}{c}95 \% \\
\text { Met }\end{array}$ \\
\hline $1.8 \%$ & & $0.30 \% \mathrm{C}_{\mathrm{E}}$ & $\begin{array}{c}0.75 \% \\
\mathrm{C}_{\mathrm{E}}\end{array}$ \\
\hline $2.4 \%$ & & $0.95 \% \mathrm{C}_{\mathrm{E}}$ & $\begin{array}{c}1.45 \% \\
\mathrm{C}_{\mathrm{E}}\end{array}$ \\
\hline $2.0 \%$ & $20 \%$ & $0.90 \% \mathrm{C}_{\mathrm{E}}$ & $\begin{array}{c}1.45 \% \\
\mathrm{C}_{\mathrm{E}}\end{array}$ \\
\hline $2.0 \%$ & $35 \%$ & $1.25 \% \mathrm{C}_{\mathrm{E}}$ & $\begin{array}{c}1.75 \% \\
\mathrm{C}_{\mathrm{E}}\end{array}$ \\
\hline
\end{tabular}

Table 7. Cost Associated with Various Gangue Components Defined by BHP for Asian Mills [12-15]

\begin{tabular}{|l|c|c|c|c|c|}
\hline & \multicolumn{5}{|c|}{ Cost in US\$/Tonne HBI Added to the EAF } \\
\hline Gangue & + Fluxes & + Additions & Yield Loss & Slag Cost & Total \\
\hline $\mathbf{S i O}_{\mathbf{2}} / \mathbf{0 . 1} \%$ & 0.156 & 0.062 & 0.135 & 0.015 & 0.368 \\
\hline $\mathbf{A l}_{2} \mathbf{O}_{\mathbf{3}} / \mathbf{0 . 1} \%$ & 0.114 & 0.062 & 0.135 & 0.015 & 0.326 \\
\hline $\mathbf{C a O} / \mathbf{0 . 1} \%$ & $(0.075)$ & 0.030 & 0.135 & 0.001 & 0.091 \\
\hline $\mathbf{M g O} / \mathbf{0 . 1} \%$ & $(0.071)$ & 0.028 & 0.135 & 0.001 & 0.093 \\
\hline
\end{tabular}

\section{CHEMICAL ENERGY APPLIED TO HBI/DRI CHARGE}

\subsection{Myth - DRI Does not add Chemical Energy to the EAF x Reality - DRI's In- Situ $\mathbf{C}$ is a More Efficient Energy Source}

The main parameters impacting EAF energy use are composition of raw materials (chemistry, metallization, energy content), operating practices (power profiles, carbon additions, foamy slag and melting practices) and furnace design (heel, $\mathrm{O}_{2}$ use and tools, Off Gas (OG) and charging systems, AC/DC). Informed, intelligent, DRI use can significantly benefit the operating results, as has been, and will be, seen $[15,18]$. Chemical energy is usually derived from combustion of carbon (contained, charged or injected), oxygen, natural gas ("fuel" being used) and "burning" elements in the bath (iron ( $\mathrm{Fe}$ ), silicon ( $\mathrm{Si}$ ), aluminum ( $\mathrm{Al}$ ) etc.). Today's new EAF technology and chemical energy tools have increased chemical energy to about $35 \%$ of total energy needs, and rising (more than $50 \%$ has been seen). This should be maximized if the economics of so doing are beneficial (VIU).

Excess \%C in the DRI is available for chemical energy input. AM Montreal East defined this (Table 6) [12]. The in-situ DRI carbon reduces FeO (hence refractory wear) and the $\mathrm{kWh} / \mathrm{Te}_{\mathrm{ls}}$ and increases $\mathrm{CO}$ generation (improved foamy slag and arc stability - especially important for the long arc DC operators). This will significantly impact site-specific carbon cost savings, provided mills can capitalize on the high energy. The substantial flat bath conditions are non-conducive to oxy-fuel burner (OFB) use and favor high velocity oxygen lances for rapid decarburization and prevention of delays/penalties in achieving the final carbon.

Greater chemical energy infers increased volume and energy loss to the OGS (nominally $17 \%$ to $22 \%$ in standard EAFs, $10 \%$ in Consteel $^{\circledR}$ and shaft furnaces and $7 \%$ in finger shaft furnaces), due to partial combustion. The OGS capacity needs to be sufficient and may need increasing and/or fan operations may need modifying. Optimization is required to capture/retain the maximum amount of energy input. This 
requires understanding the VIU of materials, source of partial combustion, balancing chemical and electrical energy [14,15], and measuring off gas temperatures and composition, in order to maximize combustion and heat retention. Hot charging metallics (solid or liquid) increases the chemical energy input and reduces energy needs significantly. Charging DRI/HBI hot negates the impact of gangue [12]. Hot metal (HM) reduces energy the most but deC (productivity loss) becomes an issue.

\section{CONCLUSIONS}

\section{1 $\mathrm{DRI} / \mathrm{HBI}$ is here to stay}

Myth - DRI/HBI is Used Only Where Scrap Quality is Bad, Availability Low or High Quality Steel Predicates x Reality - Metallics' VIU, Optimization of Charges and SOPs, Lower Cost DRI/HBI Production, Promote Increased Use

Declining iron ore quality is being improved from the mines through to pellet binders. DRI shipped tonnage today exceeds that of HBI. The greater carbon (chemical) energy efficiency of DRI's in-situ carbon can significantly alter the VIU of DRI. Site specific VIU should consider ability to handle high \%C (deC tools, OGS), use of low oxide load (gangue) DRI/HBI (organic binders) and (long-term) charge pre-heating to reduce operating costs. As standard operating procedures (SOPs) are altered to accommodate DRI use, the benefits and VIU of DRI will be maximized and detriment to the EAF operations minimized. EAF optimization will be site specific, balancing VIU of DRI and metallics with SOPs. The VIU of DRI burdens changes significantly with price. With the advent of cheap North American shale gas and the drive to invest in new DRI plants, a long term quality metallics supply can be guaranteed. DRI use will be grow as the "price will be right"!. Combining VIU, DRI specific SOPs, educated use of DRI will allow mills to produce low cost liquid steel as effectively as scrap charges.

\section{REFERENCES}

1. "2013 World Direct Reduction Statistics", MIDREX Technologies Inc., $2^{\text {nd }}$ quarter 2014.

2. Grazziuti, A., private communication, July 2014.

3. Valadares de Andrade Resende, F. et al.; "Performance Analysis of Organic Binder Compared to the Sodium Bentonite and the Over-activated Sodium Bentonite in the Production of Direct Reduction Pellets". 43 ${ }^{\text {rd }}$ Raw Materials and Iron Ore Ironmaking Seminar, September 2014, Belo Horizonte, MG, Brazil, pp. 1009-1013 (in Portuguese).

4. Hornby, S.; "EAF Optimization", 2007 Intertech Conference on Scrap Substitutes, October 2007.

5. Pereira Lima, N. el al.; "Process Routes for the Exploitation of Poor Itabirites of the Iron Quadrangle". $41^{\text {st }}$ Raw Materials and Iron Ore Ironmaking Seminar, September 2011, Vila Velha, ES, Brazil, pp. 587-594 (in Portuguese).

6. Uliana, A. et al.; "Characterization of Compact Itabirites of Alegria Mine - SAMARCO Mineração (part 1)". 42 ${ }^{\text {nd }}$ Raw Materials and Iron Ore Ironmaking Seminar, September 2012, Rio de Janeiro, RJ, Brazil, pp. 1551-1562 (in Portuguese).

7. de Pinho Rocha, J.M. et al.; "Detailed Investigation on Goethites Present in Altered Amphibolitic Itabirites (MG-Brazil)". $42^{\text {nd }}$ Raw Materials and Iron Ore Ironmaking Seminar, September 2012, Rio de Janeiro, RJ, Brazil, pp. 1754-1764 (in Portuguese).

8. Ajargo, F.M. et al.; "Methods and Experiences in Open Air DRI Storage in TenarisSiderca". $7^{\text {th }}$ IAS Ironmaking Conference, November 2009, Campana, Buenos Aires, Argentina, pp. 64-71 (in Spanish). 
9. Grazziutti, A.G. et al.; "Development of Laboratory Tests to Evaluate the Reactivity in Sponge Iron". $6^{\text {th }}$ International Congress on the Science and Technology of Ironmaking ICSTI, October 2012, Rio de Janeiro, RJ, Brazil, pp. 932-942.

10. Hassan, A., "Ore-Based Metallics 101", International Iron Metallics Association (IIMA) Seminar, October $28^{\text {th }} 2012$, Baltimore, MD, USA.

11. Noel, N. et al; "Shipping of DRI - The Nu-Iron Experience". AISTech 2014 Proceedings, pp. 823-829

12. Hornby, S; "Mini-Mill Burdening for Maximum Efficiency and Yield?", AISTech 2014 Proceedings pp. 1027-1038 and Re-published in Iron and Steel Technology, January 2015, pp. $50-62$

13. Midrex Melt Seminar, May 2000, Tuscaloosa, AL, USA.

14. $\mathrm{HBI}$ and DRI Melting Seminar, May 2002, Singapore, Co-hosted by Midrex and BHP Australia.

15. Hornby, S., "The Educated Use of DRI/HBI Improves EAF Energy Efficiency and Yield and Downstream Operating Results", European Electric Steelmaking Congress, Venice, Italy, May 2002.

16. IIMA Seminar in conjunction with the AIST Scrap Supplements \& Alternative Ironmaking VI Conference October 2012, Baltimore, MD.

17. Memoli, F. et al.; "The Use of DRI in a Consteel® EAF Process", Iron and Steel Technology, January 2015, pp.72-80.

18. Torre, F. et al.; "Results of CoJet $^{\circledR}$ technology (gas and coal fines injection system) in ACINDAR S.A., with continuous DRI charging", $15^{\text {th }}$ IAS Steelmaking Conference, San Nicolas, Argentina, November 2005, pp. 24-32 (in Spanish). 